\title{
Hydrography and Circulation Near the Crest of the East Pacific Rise Between $9^{\circ}$ and $10^{\circ} \mathrm{N}$
}

\author{
A. M. Thurnherr* J. R. Ledwellł J. W. Lavelleł L. S. Mullineaux ${ }^{\S}$ \\ *Division of Ocean and Climate Physics, Lamont-Doherty Earth Observatory, Palisades, NY 10964 \\ ${ }^{\dagger}$ Dept. of Applied Ocean Physics and Engineering, Woods Hole Oceanographic Institution, Woods Hole, \\ MA 02543 \\ ${ }^{\ddagger}$ NOAA/Pacific Marine Environmental Laboratory, Seattle, WA 98115

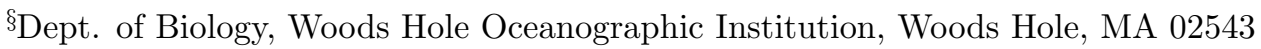

December 12, 2010

\author{
Corresponding author: \\ A. M. Thurnherr \\ Lamont-Doherty Earth Observatory \\ Palisades, NY 10964-8000 \\ ant@ldeo.columbia.edu \\ fax:(845) 365-8157
}


ABSTRACT. Topography has a strong effect on the physical oceanography over the flanks and crests of the global mid-ocean ridge system. Here, we present an analysis of the hydrography and circulation near the crest of the East Pacific Rise (EPR) between $9^{\circ}$ and $10^{\circ} \mathrm{N}$, which coincides with an integrated study site (ISS) of the RIDGE2000 program. The analysis is based primarily on survey and mooring data collected during the LADDER project, which aimed to investigate oceanographic and topographic influences on larval retention and dispersal in hydrothermal vent communities. Results indicate that the yearly averaged regional mean circulation is characterized by a westward drift of $0.5-1 \mathrm{~cm} \cdot \mathrm{s}^{-1}$ across the EPR axis and by north- and southward flows along the western and eastern upper ridge flanks, respectively. The westward drift is part of a basin-scale zonal flow that extends across most of the Pacific ocean near $10^{\circ} \mathrm{N}$, whereas the meridional currents near the ridge crest are a topographic effect. In spite of considerable mesoscale variability, which dominates the regional circulation and dispersal on weekly to monthly time scales, quasi-synoptic surveys carried out during the mooring deployment and recovery cruises indicate subinertial circulations that are qualitatively similar to the yearly averaged flow but associated with significantly stronger velocities. Weekly averaged mooring data indicate that the anticyclonically sheared along-flank flows are associated with core speeds as high as $10 \mathrm{~cm} \cdot \mathrm{s}^{-1}$ and extend $\approx 10 \mathrm{~km}$ off axis and $200 \mathrm{~m}$ above the ridge-crest topography. Near the northern limit of the study region, the Lamont Seamount Chain rises from the western ridge flank and restricts along-EPR flow to five narrow passages, where peak velocities in excess of $20 \mathrm{~cm} \cdot \mathrm{s}^{-1}$ were observed. Outside the region of the ridge-crest boundary currents the density field over the EPR near $10^{\circ} \mathrm{N}$ is characterized by isopycnals dipping into the ridge flanks. Directly above the EPR axis the ridge-crest boundary currents give rise to an isopycnal dome. During times of strong westward cross-EPR flow isopycnal uplift over the eastern flank causes the cross-ridge density field below the doming isopycnals to be asymmetric, with higher densities over the eastern than over the western flank. The data collected during the LADDER project indicate that dispersal of hydrothermal products from the EPR ISS on long time scales is predominantly to the west, whereas mesoscale variability dominates dispersal on weekly to monthly time scales, which are particularly important in the context of larval dispersal.

\section{Introduction}

Despite significant advances in measurement technology and numerical modeling, regional circulation patterns in many parts of the deep ocean remain largely unknown. This is particularly true near mid-ocean ridges, where topography affects the oceanic velocity field across a wide range of scales. Some topographic effects, such as kinematic steering and blocking, affect the circulation directly. Other topographically mediated processes, such as internal waves and hydraulic transitions, result in spatially inhomogeneous diapycnal mixing, which in turn sets up horizontal density gradients that drive secondary flows. Topographic rectification of oscillatory flows constitutes yet another mechanism affecting the oceanic circulation near topography.

The physical oceanography in the vicinity of topography is important in a variety of contexts. Topographic blocking by ridges separating deep ocean basins, for example, controls the hydrographic properties of the densest bottom waters in the downstream basins and, thus, sets the stratifications in large parts of the deep ocean. On a global scale, closing the overturning circulation requires the production of dense water at high latitudes to be balanced by buoyancy gain elsewhere. Observational evidence collected during the last few decades indicates that, except near the sea surface, diapycnal buoyancy fluxes are elevated primarily near topography, in particular over the rough flanks of mid-ocean ridges (Polzin et al., 1997; Kunze et al., 2006). On regional scales, circulation and mixing near the crests of mid-ocean ridges largely control the initial dispersal of materials released at hydrothermal sources (e.g. German et al., 1998; Thomson et al., 2003; Jackson et al., 2010; Walter et al., 2010), including the larvæ of chemosynthetic organisms, many of which are endemic to hydrothermal vent fields.

Given the distribution of hydrothermal sources along the crests of the global mid-ocean ridge system and the finite life span of invertebrate larvæ there are many open questions related to how the populations of the chemosynthetic communities associated with hydrothermal vent fields can be maintained, how sites destroyed, for example, by volcanic eruptions can be re-populated, and how newly established sites can be colonized. In order to address these questions a project called LADDER (LArval Dispersal along the Deep 
East-pacific Rise) was carried out to investigate oceanographic and topographic influences on larval retention and dispersal in hydrothermal vent communities on the crest of the East Pacific Rise (EPR) between $9^{\circ}$ and $10^{\circ} \mathrm{N}$ (Mullineaux et al., 2008). Typical for fast-spreading ridges, the EPR crest in this region hosts numerous hydrothermal sources (e.g. Baker et al., 1994), which is one of the reasons that it has been designated by the US RIDGE2000 program as an Integrated Study Site (ISS) with a "bullseye" centered at $9^{\circ} 50^{\prime} \mathrm{N}$.

Before the LADDER project was carried out, little had been known about the regional circulation near the EPR crest between $9^{\circ}$ and $10^{\circ} \mathrm{N}$. During a survey of hydrothermal plumes over the ridge crest Baker et al. (1994) found zonally asymmetric distributions of hydrothermal particle- and temperature anomalies, indicating preferentially westward cross-ridge flow in November/December 1991. Westward large-scale mean flow near the EPR crest depth $(\approx 2500 \mathrm{~m})$ in this region is consistent with the deep helium distribution in the tropical North Pacific (Lupton, 1998) and with the circulation analysis of Reid (1997) (who use the helium data as a constraint). In addition to those indirect inferences there are also current-meter records from a few mooring deployments on the EPR crest at $9^{\circ} 50^{\prime} \mathrm{N}$. One example is the $\approx 5$-month record, obtained $170 \mathrm{~m}$ above the seabed, that was used by Marsh et al. (2001) to assess the dispersal potential of a particular hydrothermal organism. The corresponding time series of sub-inertial velocities is characterized by periodic reversals of the along-ridge flow and sustained episodes of both east- and westward across-ridge flow. The zonal record mean is $0.3 \mathrm{~cm} \cdot \mathrm{s}^{-1}$ to the west, consistent with the indirect inferences of westward large-scale mean flow across the EPR crest in this region. The corresponding meridional record-mean flow is $0.8 \mathrm{~cm} \cdot \mathrm{s}^{-1}$ to the south. In their analysis of data from two zonal hydrographic sections across the EPR, including one at $9^{\circ} 30^{\prime} \mathrm{N}$, Thompson and Johnson (1996) found a $\approx 700-900 \mathrm{~m}$ thick layer where the deep isotherms and isopycnals dip downward into the ridge flanks. If the flow in this layer, which Thompson and Johnson (1996) attribute to a combination of enhanced diapycnal mixing and geothermal heating on the ridge flank, is geostrophically balanced, and if the meridional velocities vanish above the layer of dipping isotherms and isopycnals, the hydrographic data imply a southward boundary current along the western ridge flank with a mean velocity of a few $\mathrm{mm} \cdot \mathrm{s}^{-1}$.

The primary goal of the present study consists of an analysis of the regional circulation near the EPR crest between $9^{\circ}$ and $10^{\circ} \mathrm{N}$, based on observations collected during the LADDER project augmented with publicly available historical data (Section 2). Following a description of the large-scale context of the physical oceanography near the ridge crest (Section 3) pertinent aspects of the LADDER observations are presented in Section 4. Analysis of the LADDER results includes a detailed description of the density field over the EPR crest and upper flanks (Section 4.1), yearly averaged mean velocities recorded by instruments deployed on the LADDER mooring array (Section 4.2), weekly-averaged velocities observed during a 1-month tracer-release experiment (Section 4.3), as well as details of the circulation observed near the Lamont Seamount Chain rising above the upper western EPR flank near $10^{\circ} \mathrm{N}$ (Section 4.4). Synthesis of the main results (Section 5) is followed by a discussion in Section 6 .

\section{Methods}

\subsection{Instruments and Data}

Work carried out in the context of the LADDER project includes larval sampling using pumps and sediment traps (Mullineaux et al., prep), an $\mathrm{SF}_{6}$ tracer-release experiment (Jackson et al., 2010), a one-year deployment of a mooring array, three quasi-synoptic regional surveys carried out with Conductivity-Temperature-Depth (CTD) and Lowered Acoustic Doppler Current Profiler (LADCP) instruments, as well as numerical experiments with 2- and 3-dimensional regional circulation models (McGillicuddy et al., 2010; Lavelle et al., 2010).

During the first LADDER cruise (LADDER-1; Oct. 30 - Nov. 15, 2006) 7 physical oceanography moorings were deployed in a cross-shaped configuration extending $\approx 35 \mathrm{~km}$ from the array center on the EPR crest at $9^{\circ} 30^{\prime} \mathrm{N}$ - see Fig. 4 below for mooring locations and station names. The center of the mooring array coincided with the release location of $\mathrm{SF}_{6}$ in the LADDER tracer-dispersion experiment (Jackson et al., 2010). The three axial moorings (NA, CA and SA) and the two moorings farthest from the ridge axis (EF and WF) were each equipped with three Aanderaa RCM-11 current meters. The uppermost instruments 
recorded the velocities near $2450 \mathrm{~m}$ in the core of the hydrothermal plumes observed in this region (Baker et al., 1996; Jackson et al., 2010). The lowermost instruments on the three axial moorings were located $6 \mathrm{~m}$ above the seabed, near the rim depth of the shallow axial trough running along the EPR crest in this region (Fornari et al., 1998). Each axial mooring additionally had an instrument placed $24 \mathrm{~m}$ above the seabed. The lower two instruments on the EF and WF moorings were installed near the EPR crest depth (nominally $2550 \mathrm{~m}$ ) and $\approx 60 \mathrm{~m}$ above the seabed. All current meters were programmed to sample the velocity field every 20 min. With the exception of the EF mooring, where the deepest instrument flooded during deployment, all current meters returned full year-long records without any indications for instrument problems.

Two additional moorings equipped with McLane Moored Profilers (MMPs) were deployed on the western ridge flank $\approx 10$ and $25 \mathrm{~km}$ off axis (W1 and W3 in Fig. 4 below). At W1, velocity profiles were recorded every $7 \mathrm{hr}$ between 2300 and $2775 \mathrm{~m}(\approx 10$ m.a.b. $=$ meters above the bottom $)$. Since this MMP was ballasted light, the downcasts took about twice as long to execute $(\approx 60 \mathrm{~min})$ than the upcasts $(\approx 30 \mathrm{~min})$. Inspection of the raw magnetometer data from the W1 MMP indicates that a compass problem (non-linear magnetometer response) developed after 176 days (603 good profiles). At W3, velocity profiles were recorded every $8: 50 \mathrm{hr}$ between 2255 and $3025 \mathrm{~m}(\approx 10 \mathrm{~m}$.a.b.). This MMP, too, was ballasted light, resulting in longer downcast$(\approx 80 \mathrm{~min}$, initially) than upcast-times $(\approx 50 \mathrm{~min})$. After the first 2 months of deployment the downcast-times started increasing significantly as the instrument began struggling against buoyancy and after a further 2 months the termination depths of the downcasts became progressively shallower. Toward the end of the deployment the typical maximum depth of the W3 MMP profiles had decreased to $\approx 2800 \mathrm{~m}$.

During LADDER-1, a survey of the regional hydrography and velocity field was carried out with a SBE 911 CTD mounted on a frame together with a rosette and one or two Teledyne RDI Workhorse $300 \mathrm{kHz}$ ADCPs. The CTD was equipped with sensors for pressure, temperature and conductivity. Temperature and conductivity were measured with two thermistors and two conductivity cells, respectively. The ADCPs were programmed to collect single-ping velocity "ensembles" in beam coordinates. The bin length was set to $8 \mathrm{~m}$, the blanking distance to $0 \mathrm{~m}$ and data from the first bin were excluded from processing. In order to minimize the effects of previous-ping interference from the seabed, alternating ping intervals of 1.5 and $2 \mathrm{~s}$ were used. During the LADDER-1 survey, 36 full-depth profiles were collected on 15 stations in a crossshaped pattern coinciding with the mooring array but with higher spatial resolution, in particular along the EPR crest and on the eastern ridge flank - for station locations see Fig. 5 below. In order to be able to account for high-frequency variability, most of the LADDER-1 CTD/LADCP stations were occupied two or three times at different phases of the semidiurnal tide, which accounts for $55-72 \%$ of the velocity variance on time scales shorter than 5 days in this region. (The inertial period at this latitude is $\approx 3$ days.) The good agreement of vertical velocity shear of ensemble-averaged LADCP profiles collected on the ridge flanks during LADDER-1 with corresponding geostrophic estimates (Fig. 12 below) implies that tidal influence in the ensemble averages is significantly reduced compared to individual LADCP profiles.

The second LADDER cruise (LADDER-2; Dec. 12, 2006 - Jan. 3, 2007) was primarily dedicated to sampling the tracer released during LADDER-1. CTD/LADCP data were collected with instruments identical to those used during LADDER-1 at all 100 tracer-sampling stations shown in Fig. 1 of Jackson et al. (2010). However, since tidal variability dominates instantaneous velocity samples in this region, and since only a few of the LADDER-2 stations were occupied multiple times (and without regard to the tidal phase) only a small subset of the LADDER-2 survey data is used here. During the third LADDER cruise (LADDER-3; Nov. 15 - Dec. 1, 2007) the mooring array was recovered and an additional CTD/LADCP survey was carried out, again with identical instruments. About a third of the 50 LADDER-3 CTD/LADCP profiles were collected on stations occupied during LADDER-1 while most of the remainder were used to sample the velocity field and hydrography near the Lamont Seamount Chain rising above the western flank of the EPR near $10^{\circ} \mathrm{N}$ (for details, see Section 4.4 below).

In addition to the data collected during LADDER, this study makes use of hydrographic and helium isotope measurements obtained during World Ocean Circulation Eperiment (WOCE) hydrographic sections (in particular the zonal P04 section along $9^{\circ} 30^{\prime} \mathrm{N}$ ) in the tropical north Pacific. Furthermore, the trajectory of a METOCEAN PROVOR float, which was deployed in May 2006 on the EPR crest at $9^{\circ} 50^{\prime} \mathrm{N}$, is also used. The float was programmed to drift at its maximum rated pressure $(2000 \mathrm{dbar}$, corresponding to a depth of 
$\approx 1980 \mathrm{~m}$ ) and to surface every 30 days for $18 \mathrm{hr}$ for data telemetry and position fixes. The float carried out 29 complete drift cycles before failing to re-surface.

\subsection{Data Processing}

The velocities from the Aanderaa current meters were corrected for magnetic declination. Processing of MMP velocities is significantly more complex and potentially involves corrections for heading errors, as well as for velocity bias and scale of the FSI acoustic travel-time current meters (Toole, 2001). In order to determine heading corrections, post-cruise spin tests were carried out. In the case of the W1 instrument the postcruise test indicates sizeable heading-dependent compass errors $\left(15^{\circ}\right.$ max., $\left.9^{\circ} \mathrm{rms}\right)$ while the errors of the W3 compass were significantly smaller $\left(<1.5^{\circ} \mathrm{rms}\right)$. Since the $\mathrm{W} 1$ compass errors detected during the post-cruise spin test are likely related to the non-linear magnetometer response that developed while the instrument was in the water (Section 2.1), no compass correction was applied and only the initial portion of the W1 velocity record was used. In order to correct for velocity bias, the in situ method of Toole (2001) was applied. It was found that this calibration procedure has a strong effect on the velocities, changing the direction of the record-averaged mean flow recorded by the W1 instrument by up to $20^{\circ}$ and reducing the corresponding mean velocity magnitude in the core of the along-flank boundary current (see Section 4.3 below) from 4.1 to $2.4 \mathrm{~cm} \cdot \mathrm{s}^{-1}$. In terms of flow direction, the calibrated velocities are clearly superior to the uncalibrated ones as indicated, for example, by histograms of the angle of flow incidence relative to the instrument (not shown). Since no laboratory calibrations of the FSI current meters were carried out the accuracy of the velocity scaling could not be verified, but comparisons of weekly averaged velocities recorded on the W3 and WF moorings (e.g. Fig. 7 below) suggest that MMP scale errors are small.

During each CTD/LADCP survey the salinity calibration of the CTD was monitored with water samples analyzed on a Guildline Autosal salinometer. The accuracy of the salinity data determined from the Autosal measurements is $\leq 10^{-3}$ for LADDER- 1 and -2 , and $\leq 2 \times 10^{-3}$ for LADDER-3. The $r m s$ salinity scatter on deep isopycnals during LADDER-1 is $\approx 10^{-3}$, as is the cruise-to-cruise salinity uncertainty between LADDER1 and -2 (Jackson et al., 2010). Near the EPR crest, a salinity bias of $10^{-3}$ corresponds to a potential-density error of $<10^{-3} \mathrm{~kg} \cdot \mathrm{m}^{-3}$. The temperature accuracy is estimated from the mean differences between the two CTD temperature sensors; the corresponding values for the LADDER-1, -2 and -3 surveys are $\approx 5 \times 10^{-4}{ }^{\circ} \mathrm{C}$, $10^{-3 \circ} \mathrm{C}$, and $1.5 \times 10^{-3}{ }^{\circ} \mathrm{C}$, respectively. Near the EPR crest, a temperature bias of $10^{-3 \circ} \mathrm{C}$ correpsonds to a potential-density error of $\approx 10^{-4} \mathrm{~kg} \cdot \mathrm{m}^{-3}$. The manufacturer-specified nominal accuracy of the CTD pressure sensor is $\approx 1$ dbar.

The LADCP data collected during the three LADDER cruises were processed dozens of times with different programs and velocity-referencing constraints in the context of an investigation of LADCP velocity errors (Thurnherr, 2010). Based on comparisons with nearby current-meter measurements the rms errors associated with the individual velocity components of the LADDER LADCP data, processed with the LDEO software (Version IX_5) and constrained by navigational data, shipboard-ADCP and bottom-tracking, are $<3 \mathrm{~cm} \cdot \mathrm{s}^{-1}$ near the seabed and $<4 \mathrm{~cm} \cdot \mathrm{s}^{-1}$ throughout the water column. Only the data from the downwardlooking ADCP are used for the LADDER-3 LADCP profiles because of inconsistencies between the ADCP data from the two heads used during that cruise (Thurnherr, 2010).

\section{Large-Scale Context}

The study region of the LADDER project was centered on the crest of the EPR near $9^{\circ} 30^{\prime} \mathrm{N}$. Hydrographic and tracer data were collected in 1989 along $9^{\circ} 30^{\prime} \mathrm{N}$ during a trans-Pacific cruise both known as the EPIC transpacific section at $10^{\circ} \mathrm{N}$ (Thompson and Johnson, 1996) and as WOCE P04. On the basin scale, the distribution of terrigenic helium along $9^{\circ} 30^{\prime} \mathrm{N}$ is dominated by a plume with a core depth between 2000 and $2500 \mathrm{~m}$ (Fig. 1, shading and light contours). The highest helium concentrations are found near the EPR crest at $104^{\circ} 15^{\prime} \mathrm{W}$. Meridional WOCE cross-sections of the plume at $110^{\circ} \mathrm{W}(\mathrm{P} 18), 135^{\circ} \mathrm{W}(\mathrm{P} 17), 150^{\circ} \mathrm{W}(\mathrm{P} 16)$, $179^{\circ} \mathrm{E}(\mathrm{P} 14), 165^{\circ}(\mathrm{P} 13)$ and $137^{\circ} \mathrm{E}(\mathrm{P} 09)$ all show a helium core meridionally centered at $10 \pm 5^{\circ} \mathrm{N}$, i.e. the plume extends almost exactly zonally westward over more than $13,000 \mathrm{~km}$. Overall, the helium distribution 


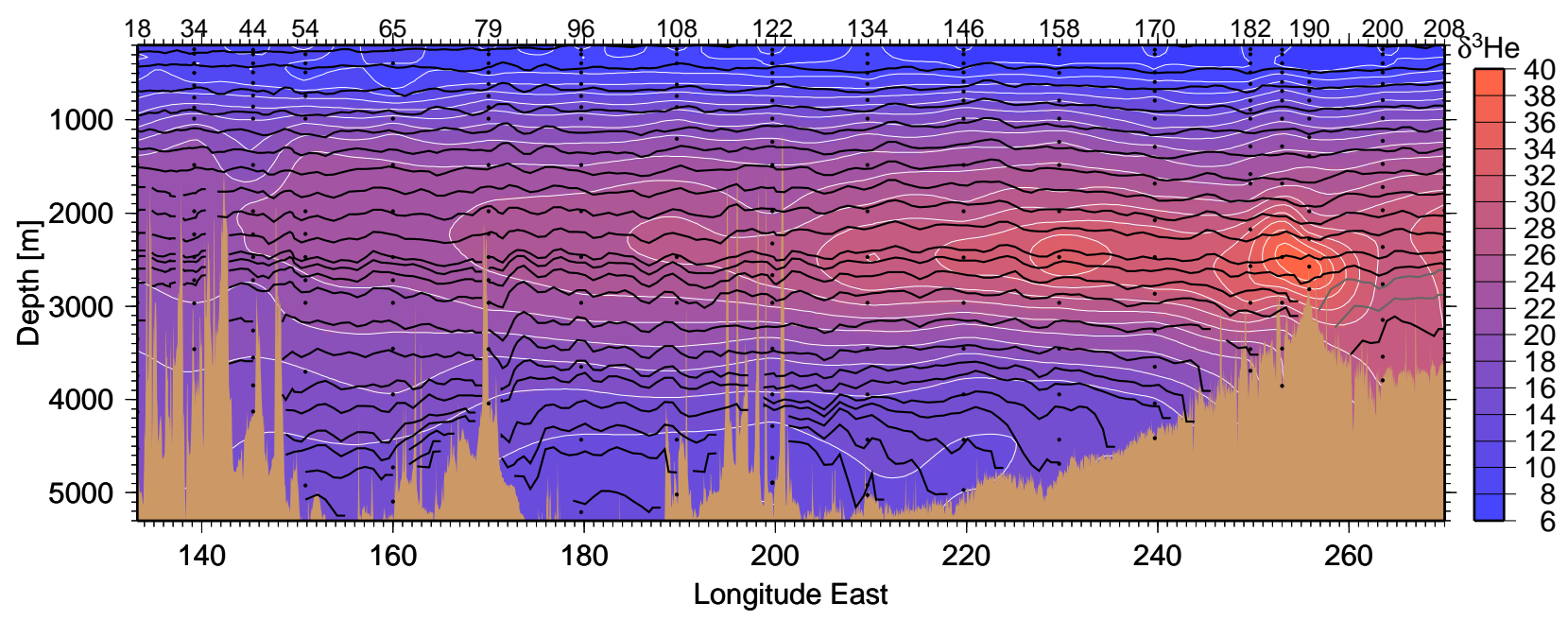

Fig. 1: Trans-Pacific section of $\delta^{3} \mathrm{He}$ (shading and light contours) and neutral density (dark contours) along $9^{\circ} 30^{\prime} \mathrm{N}$ measured during WOCE P04 in 1989. The bottle-sample locations of $\delta^{3} \mathrm{He}$, a measure of helium derived from the Earth's mantle (Clarke et al., 1969), are marked with black dots and the corresponding station numbers are printed above the panel. Above the crest depth of the EPR, density contour levels were chosen to be uniformly spaced in depth. Below crest depth, the density contour levels were selected from the bottom densities of manually selected stations from the EPR flanks, in order to minimize the effect of interpolation errors on the isopycnal grounding locations. The isopycnals were smoothed with a $0.5^{\circ}$-wide $(\sigma)$ Gaussian filter. In order to clarify the plot, four isopycnals are not plotted in the deep basin near the dateline (between stations 78 and 108). Additionally, the two grey-shaded density contours are only plotted in the Guatemala Basin east of the EPR crest. The profile from the station closest to the EPR crest (\#190) was truncated at crest depth in order to avoid contouring across the topography - see also Fig. 3 below.

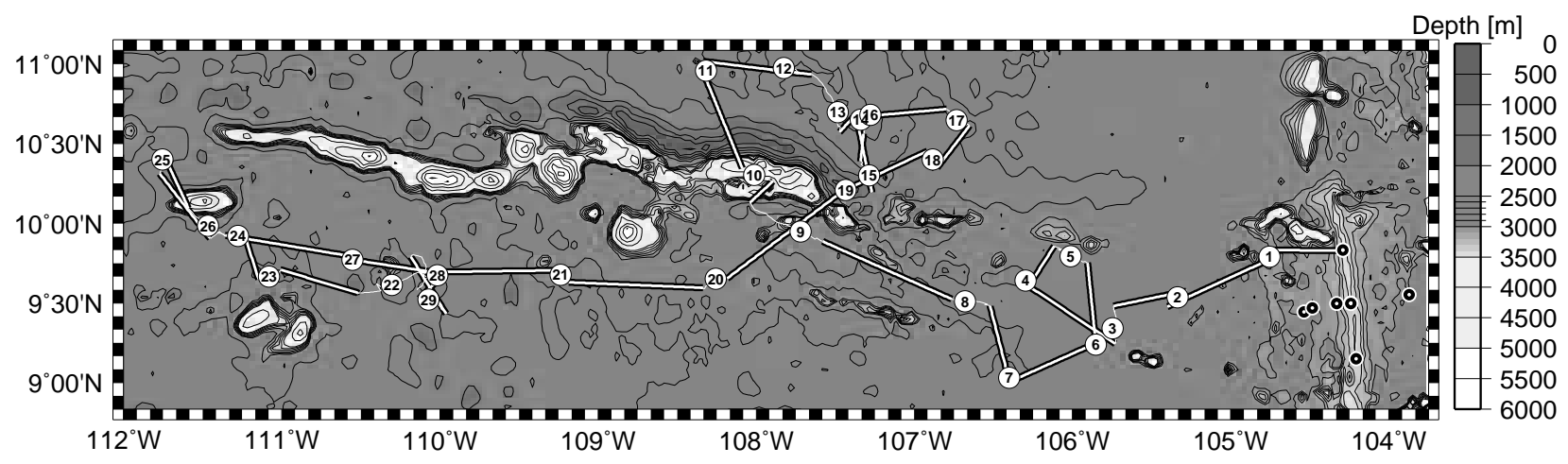

Fig. 2: 900-day track of a float released on May 17, 2006 at $9^{\circ} 50^{\prime} \mathrm{N}$ on the EPR crest. Thick line segments indicate 30-day displacements at $1980 \mathrm{~m}$; thin lines indicate float trajectories during the $18 \mathrm{hr}$-long surface intervals, which are numbered consecutively. The circles near the EPR crest in the lower-right corner show the LADDER mooring locations. Crosses indicate WOCE P04 station positions.

in the deep tropical north Pacific is consistent with a source on the EPR crest and predominantly westward mean flow (Lupton, 1998). As the plume is advected to the west its core is progressively found on lighter isopycnals (dark contours in Fig. 1). This effect can be caused both by vertical shear in the mean zonal flow and by vertical gradients in the eddy-diffusive helium fluxes along the dispersal path of the plume. 


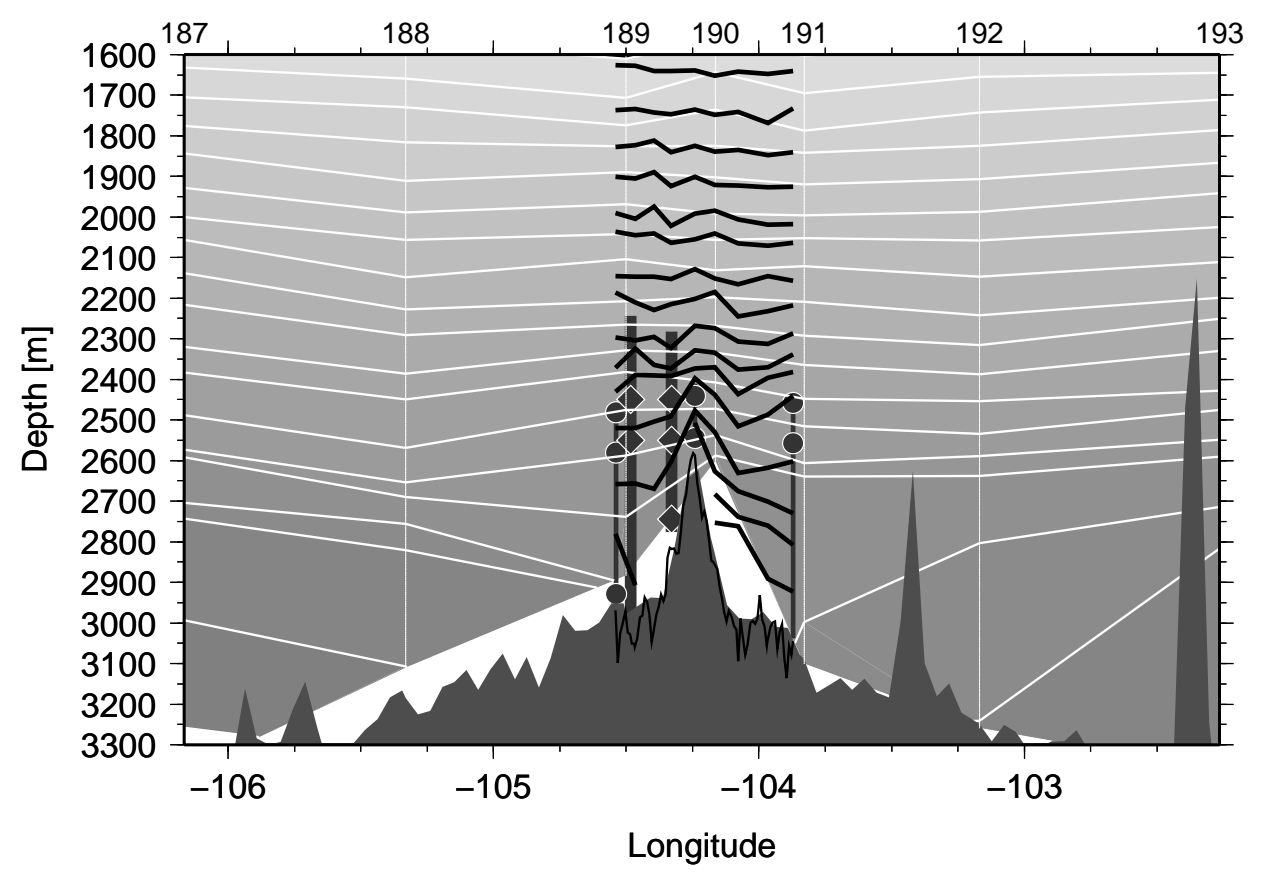

Fig. 3: Potential density section across the EPR crest at $9^{\circ} 30^{\prime} N$. Shading and light contours: WOCE P04 neutral densities; the corresponding station numbers are printed above the panel. Dark contours: LADDER-1 neutral densities; for station locations, see Fig. 5 below. Bullets: current meters of the LADDER array; the deepest axial instruments moored 6 m.a.b. are not shown. Thick vertical lines over the western ridge flank: LADDER MMP moorings. Diamonds: depths of the MMP records shown in Figures 4 and 7 below. Black line: SeaBeam topography (data from Macdonald et al., 1992) across the center of the LADDER mooring array.

The track of a float that was deployed in May 2006 over the EPR crest at $9^{\circ} 50^{\prime} \mathrm{N}$ and that drifted for 900 days near $2000 \mathrm{~m}$ shows predominantly westward advection, although about a third of the individual drift cycles were associated with eastward displacements (Fig. 2). During its voyage, the float carried out three anticyclonic loops, each lasting several months and associated with meridional displacements of $\approx 100 \mathrm{~km}$, although the net meridional displacement over the float's entire life time was only $30 \mathrm{~km}$. The net zonal displacement was $640 \mathrm{~km}$, which corresponds to a mean westward velocity with a speed of $0.8 \mathrm{~cm} \cdot \mathrm{s}^{-1}$. Thus, both the helium and float data indicate mean westward flow across the EPR crest near $9^{\circ} 30^{\prime} \mathrm{N}$. It is noted that the high $\delta^{3} \mathrm{He}$ observed in the Guatemala basin east of the EPR crest (Fig. 1) does not require an additional source or eastward mean flow as eddy-diffusive effects, e.g. associated with the oceanic mesoscale, can cause dispersion of passive tracers against a sufficiently weak mean flow (e.g. Speer et al., 2003).

\section{LADDER Observations}

\subsection{Ridge-Crest Hydrography}

Typical for hydrographic sections across mid-ocean ridges, the deep isopycnals observed during WOCE P04 dip downward into both flanks of the EPR (Fig. 1). This effect is sometimes attributed to elevated levels of diapycnal mixing over the sloping and topographically rough ridge flanks, possibly in combination with geothermal heating (e.g. Thompson and Johnson, 1996; Thurnherr and Speer, 2003). Zooming in on the EPR reveals that the hydrography near the crest is complex and associated with horizontal scales that are 


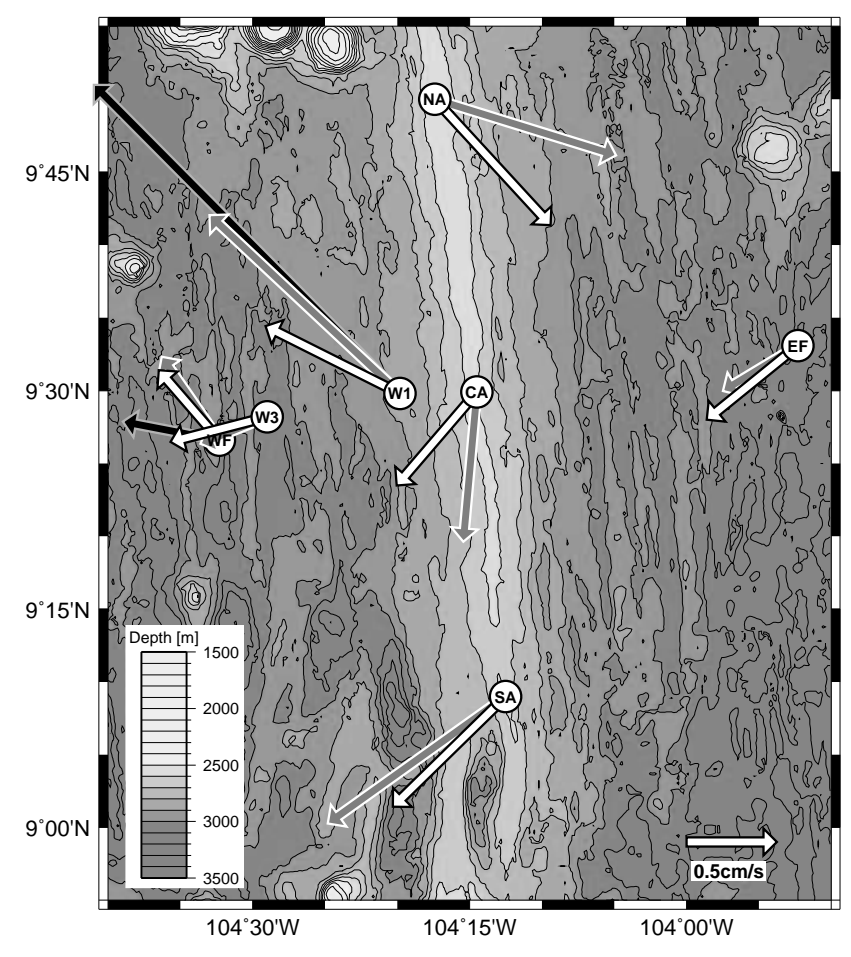

Fig. 4: Record-averaged current-meter velocities from the LADDER mooring array; the 6-month W1 record is approximately half as long as all the others (Table 1 ). White, grey, and black arrows show velocities at plume level $(\approx 2450 \mathrm{~m})$, crest level $(20 \mathrm{~m}$.a.b. on axis, $\approx 2550 \mathrm{~m}$ over the ridge flanks) and 60 m.a.b. ( $2745 \mathrm{~m}$ at $\mathrm{W} 1,2930 \mathrm{~m}$ at $\mathrm{WF})$, respectively. The depths of the velocity records are indicated with bullets and diamonds in Fig. 3.

too small to be resolved by the WOCE station spacing (Fig. 3). The isopycnal surfaces dome upward over the ridge crest both in the WOCE P04 data and in a cross-ridge section along $9^{\circ} 30^{\prime} \mathrm{N}$ occupied during LADDER-1. During LADDER-1 this doming extended at least up to $2200 \mathrm{~m}$ whereas the corresponding vertical extent is difficult to estimate from the WOCE data because the station spacing $(\approx 37 \mathrm{~km}$ over the crest) is larger than the width of the isopycnal dome (20-30 km in the LADDER-1 data). Beyond the doming region the isopycnals at and below crest depth dip downward into the western ridge flank in both the WOCE and LADDER-1 data. Over the eastern ridge flank the isopycnals in the WOCE data dip downward into the topography east of station 191 (i.e. outside the LADDER-1 sampling region). The LADDER-1 data, on the other hand, show the isopycnals below crest depth rising toward the west between the eastern edge of the sampling region and the ridge crest. As a result, the density stratification below crest depth on the western EPR flank close to the ridge axis was significantly weaker than the stratification on the eastern flank. This is apparent from the fact that the two deepest LADDER-1 density contours in Fig. 3 do not appear on the western flank at all. Farther down on the ridge flanks, i.e. outside the LADDER sampling region, the situation is reversed with significantly weaker stratification east of the EPR crest than in the west (WOCE-derived density contours in Figures 1 and 3).

\subsection{Yearly Averaged Mean Flow}

Record-averaged velocities from the LADDER mooring array are shown in Fig. 4. The corresponding currentmeter locations and MMP record depths are marked with bullets and diamonds in Fig. 3. Table 1 lists additional instrument details of the records nominally collected at $2450 \mathrm{~m}$, which corresponds to the core depth 


\begin{tabular}{lllll|rr} 
id & location & rec. length & depth & instr. & zonal velocity & meridional velocity \\
\hline $\mathrm{NA}$ & $9^{\circ} 50.0^{\prime} \mathrm{N} 104^{\circ} 17.4^{\prime} \mathrm{W}$ & 388 days & $2430 \mathrm{~m}$ & RCM-11 & $0.5( \pm 0.9) \mathrm{cm} \cdot \mathrm{s}^{-1}$ & $-\mathbf{0 . 6}( \pm \mathbf{0 . 6}) \mathrm{cm} \cdot \mathrm{s}^{-1}$ \\
$\mathrm{CA}$ & $9^{\circ} 29.9^{\prime} \mathrm{N} 104^{\circ} 14.5^{\prime} \mathrm{W}$ & 381 days & $2440 \mathrm{~m}$ & $\mathrm{RCM}-11$ & $\mathbf{- 0 . 5}( \pm \mathbf{0 . 6}) \mathrm{cm} \cdot \mathrm{s}^{-1}$ & $-0.4( \pm 0.7) \mathrm{cm} \cdot \mathrm{s}^{-1}$ \\
$\mathrm{SA}$ & $9^{\circ} 09.0^{\prime} \mathrm{N} 104^{\circ} 12.5^{\prime} \mathrm{W}$ & 366 days & $2440 \mathrm{~m}$ & $\mathrm{RCM}-11$ & $\mathbf{- 0 . 6}( \pm \mathbf{0 . 7}) \mathrm{cm} \cdot \mathrm{s}^{-1}$ & $-0.6( \pm 0.9) \mathrm{cm} \cdot \mathrm{s}^{-1}$ \\
$\mathrm{EF}$ & $9^{\circ} 33.1^{\prime} \mathrm{N} 103^{\circ} 52.3^{\prime} \mathrm{W}$ & 392 days & $2460 \mathrm{~m}$ & $\mathrm{RCM}-11$ & $\mathbf{- 0 . 6}( \pm \mathbf{0 . 6}) \mathrm{cm} \cdot \mathrm{s}^{-1}$ & $-\mathbf{0 . 5}( \pm \mathbf{0 . 4}) \mathrm{cm} \cdot \mathrm{s}^{-1}$ \\
$\mathrm{WF}$ & $9^{\circ} 26.6^{\prime} \mathrm{N} 104^{\circ} 32.3^{\prime} \mathrm{W}$ & 384 days & $2480 \mathrm{~m}$ & $\mathrm{RCM}-11$ & $\mathbf{- 0 . 3}( \pm \mathbf{0 . 4}) \mathrm{cm} \cdot \mathrm{s}^{-1}$ & $\mathbf{0 . 4}( \pm \mathbf{0 . 4}) \mathrm{cm} \cdot \mathrm{s}^{-1}$ \\
$\mathrm{~W} 1$ & $9^{\circ} 29.8^{\prime} \mathrm{N} 104^{\circ} 19.8^{\prime} \mathrm{W}$ & 176 days & $2450 \mathrm{~m}$ & $\mathrm{MMP}$ & $\mathbf{- 0 . 7}( \pm \mathbf{0 . 9}) \mathrm{cm} \cdot \mathrm{s}^{-1}$ & $0.4( \pm 0.9) \mathrm{cm} \cdot \mathrm{s}^{-1}$ \\
$\mathrm{~W} 3$ & $9^{\circ} 28.2^{\prime} \mathrm{N} 104^{\circ} 29.0^{\prime} \mathrm{W}$ & 333 days & $2450 \mathrm{~m}$ & $\mathrm{MMP}$ & $\mathbf{- 0 . 5}( \pm \mathbf{0 . 4}) \mathrm{cm} \cdot \mathrm{s}^{-1}$ & $-0.1( \pm 0.6) \mathrm{cm} \cdot \mathrm{s}^{-1}$
\end{tabular}

Table 1: Instrument details and record-average velocities near $2450 \mathrm{~m}$ obtained on the LADDER mooring array; velocity components that are considered (marginally) significantly different from zero are shown in bold.

of the neutrally buoyant hydrothermal plumes observed in this region (Baker et al., 1994; Jackson et al., 2010), as well as the corresponding record means with standard-error estimates derived using the method of Flierl and McWilliams (1978). As this method yields conservative estimates we consider the yearly averages marginally significant, as long as the standard-error estimates are only slightly $\left(1-2 \mathrm{~mm} \cdot \mathrm{s}^{-1}\right)$ larger than the corresponding means. Except for the current meters on the northern axial mooring at $9^{\circ} 50^{\prime} \mathrm{N}$ (NA) all instruments recorded mean zonal flow to the west, with record-averaged zonal speeds ranging from 0.3 to $0.7 \mathrm{~cm} \cdot \mathrm{s}^{-1}$. The meridional velocities recorded directly on the EPR axis as well as over the eastern flank indicate mean southward flow during LADDER. Over the western ridge flank, on the other hand, the record-averaged currents at W1 and WF were to the north while weak southward mean flow was recorded at W3 throughout the entire depth range where velocities were sampled during the full deployment period ( $\approx 2300-2800 \mathrm{~m}$; Section 2.1). Comparing the record-averaged velocities at plume level to the corresponding standard errors (Table 1) indicates that the westward zonal velocities are all marginally statistically significant, whereas the apparent eastward flow at NA is not. The only plume-level meridional velocities that are (marginally) statistically significant are those at NA, EF and WF.

Data from the axial moorings (NA, CA and SA) all show slightly higher record-averaged speeds 20 m.a.b. than at plume level (Fig. 4), indicating bottom intensification of the low-frequency flow above the EPR crest. At 6 m.a.b., the mean velocities are $\approx 50 \%$ weaker than the corresponding velocities recorded 20 m.a.b., consistent with the effects of a turbulent bottom-boundary layer. Furthermore, the deepest velocities are associated with approximately southward directions (not shown), which likely reflects topographic steering by the shallow axial trough running along the EPR crest in this region (Fornari et al., 1998).

The largest record-averaged velocities of $2.4( \pm 1.0) \mathrm{cm} \cdot \mathrm{s}^{-1}$ were observed between 2730 and $2750 \mathrm{~m}(60-80 \mathrm{~m} . \mathrm{a} . \mathrm{b}$. by the MMP deployed at W1 (Fig. 4). Between the upper cycling limit of this profiler (2300 m) and the velocity maximum the record-averaged speed increases monotonically with depth. Inspection of multibeam bathymetry near the W1 mooring location indicates that the flow direction in the velocity core $\left(\approx 320^{\circ}\right.$ true) is parallel to the topographic contours upstream of the mooring (not shown). The maximum velocity variance associated with the sub-inertial flow at this location is oriented in the same direction, whereas the semidiurnal tidal variance, which dominates the super-inertial variability, is oriented approximately perpendicularly along $70^{\circ}$ true (not shown). Therefore, $320^{\circ}$ true is taken as the local along-flank direction at the W1 mooring site. (The mean along-flank velocity profile shown in Fig. 4 of McGillicuddy et al. (2010) is also oriented along $320^{\circ}$ true.)

\subsection{Circulation During the Tracer Release Experiment}

Between mid-November 2006 and the beginning of January 2007 a tracer-dispersion experiment was carried out in the LADDER study region (Jackson et al., 2010). The LADCP data from the tracer-release cruise (LADDER-1; Oct. 30 - Nov. 15) reveal a coherent mean circulation characterized by a broad westward drift of several $\mathrm{cm} \cdot \mathrm{s}^{-1}$ across the EPR and predominantly southward flow of similar magnitude along the eastern ridge flank at and below the core depth of the regional hydrothermal plumes (Fig. 5). On the western ridge 

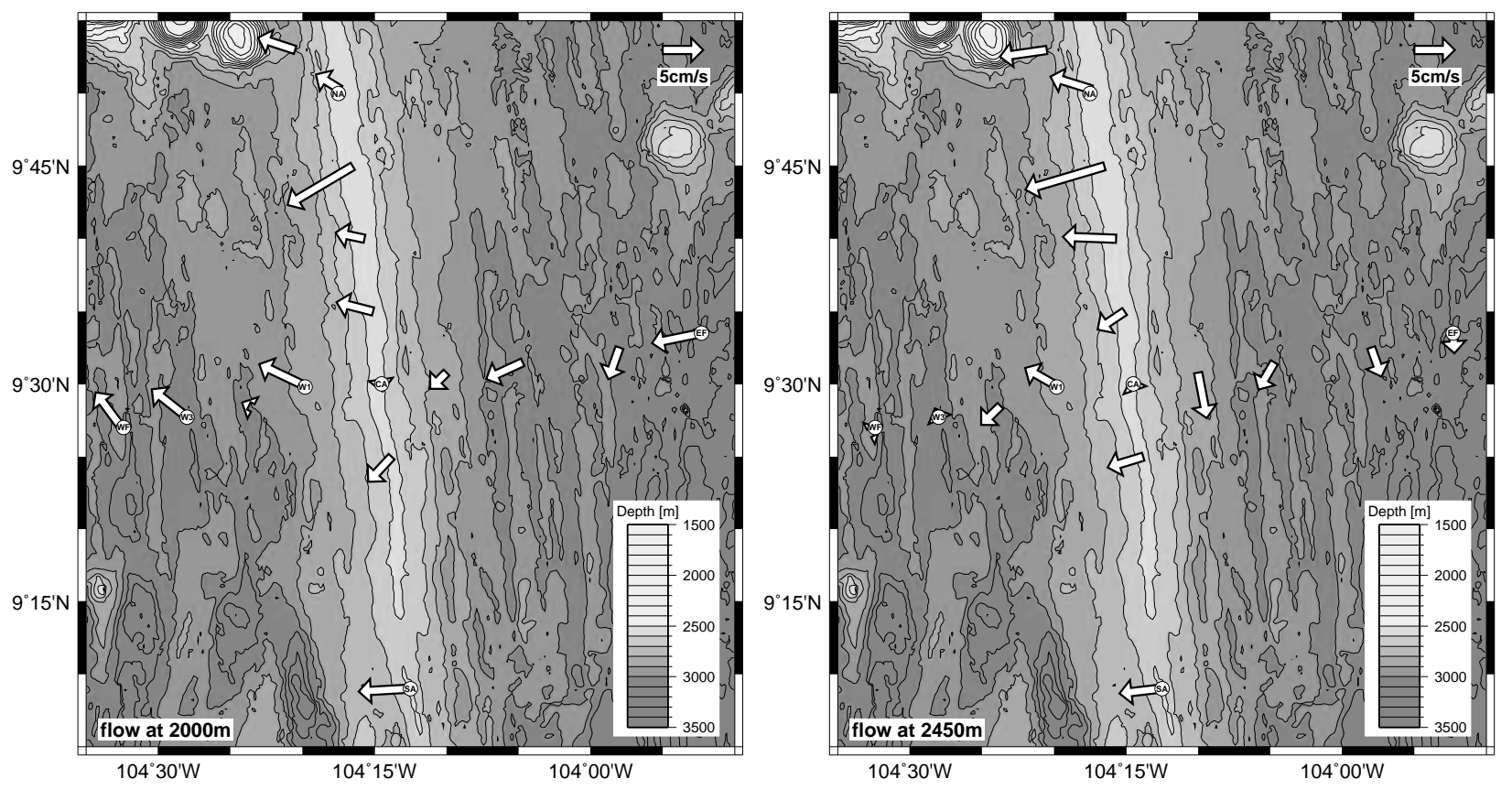

Fig. 5: LADCP-derived velocities observed during LADDER-1. Each arrow represents an average over a $100 \mathrm{~m}$-thick layer using the data from all profiles collected at a particular station. Except for the northernand southernmost locations, each station was occupied two or three times at different phases of the semidiurnal tide. Left panel: Flow at $2000 \mathrm{~m}$. Right panel: Flow at $2450 \mathrm{~m}$ near the core depth of the regional hydrothermal plumes.

flank at $2000 \mathrm{~m}$, i.e. $500-600 \mathrm{~m}$ above the EPR crest, the meridional component of the LADDER-1 LADCP velocities was consistently to the north (left panel). At plume level (right panel), northward flow over the western ridge flank was restricted to the first station west of the ridge crest (W1). A cross-ridge section of velocity constructed from the LADDER- 1 profiles at $9^{\circ} 30^{\prime} \mathrm{N}$ indicates that the westward flow across the EPR crest generally increased upward and extended all the way to the sea surface (Fig. 6). The meridional velocities, on the other hand, were more variable with the comparatively strong along-flank flows restricted to the steep (rise/run $\approx 0.03$ ) inner flanks of the EPR (roughly between stations W2 and E2).

On Nov. 12 2006, shortly before the end of the LADDER-1 cruise, $3 \mathrm{~kg}$ of $\mathrm{SF}_{6}$ were injected a few $\mathrm{m}$ above the seabed on the EPR crest at $9^{\circ} 30^{\prime} \mathrm{N}$ (Jackson et al., 2010). Approximately a month after the tracer release the distribution of $\mathrm{SF}_{6}$ was sampled during the 3-week-long LADDER-2 cruise (Dec. 15 - Jan. 3). In the first four weeks after tracer injection the sub-inertial flow at the tracer-release location in the center of the mooring array $(\mathrm{CA})$ at $2450 \mathrm{~m}$ gradually turned clockwise from approximately northwestward while first increasing and then decreasing in strength (Fig. 7, left panel). A similar evolution of the plume-level sub-inertial velocities was observed $10 \mathrm{~km}$ off axis over the western flank at $9^{\circ} 30^{\prime} \mathrm{N}$ (W1), as well as on-axis at $9^{\circ} 50^{\prime} \mathrm{N}(\mathrm{NA})$ and at $9^{\circ} 10^{\prime} \mathrm{N}(\mathrm{SA})$. Clockwise turning of the sub-inertial currents at $2450 \mathrm{~m}$ was also observed at $9^{\circ} 30^{\prime} \mathrm{N} 30-35 \mathrm{~km}$ off axis on the western flank (W3 \& WF) although the velocities there were significantly weaker and generally dominated by the westward zonal component. The plume-level velocities recorded on the eastern ridge flank $35 \mathrm{~km}$ off axis $(\mathrm{EF})$, on the other hand, exhibited neither the consistent clockwise turning nor the velocity maximum between Nov. 26 and Dec. 2. During the following three weeks (Dec. $10-$ Dec. 30), which coincide approximately with the tracer-sampling cruise (LADDER-2), the regional flow field at $2450 \mathrm{~m}$ was markedly different with predominantly southward flow recorded over the entire mooring array and comparatively small temporal variability (Fig. 7, right panel).

Weekly averaged along- and cross-flank velocity profiles observed by the W1 MMP during the tracerrelease experiment indicate consistently northward along-flank flow during the first 4 weeks, followed by 3 


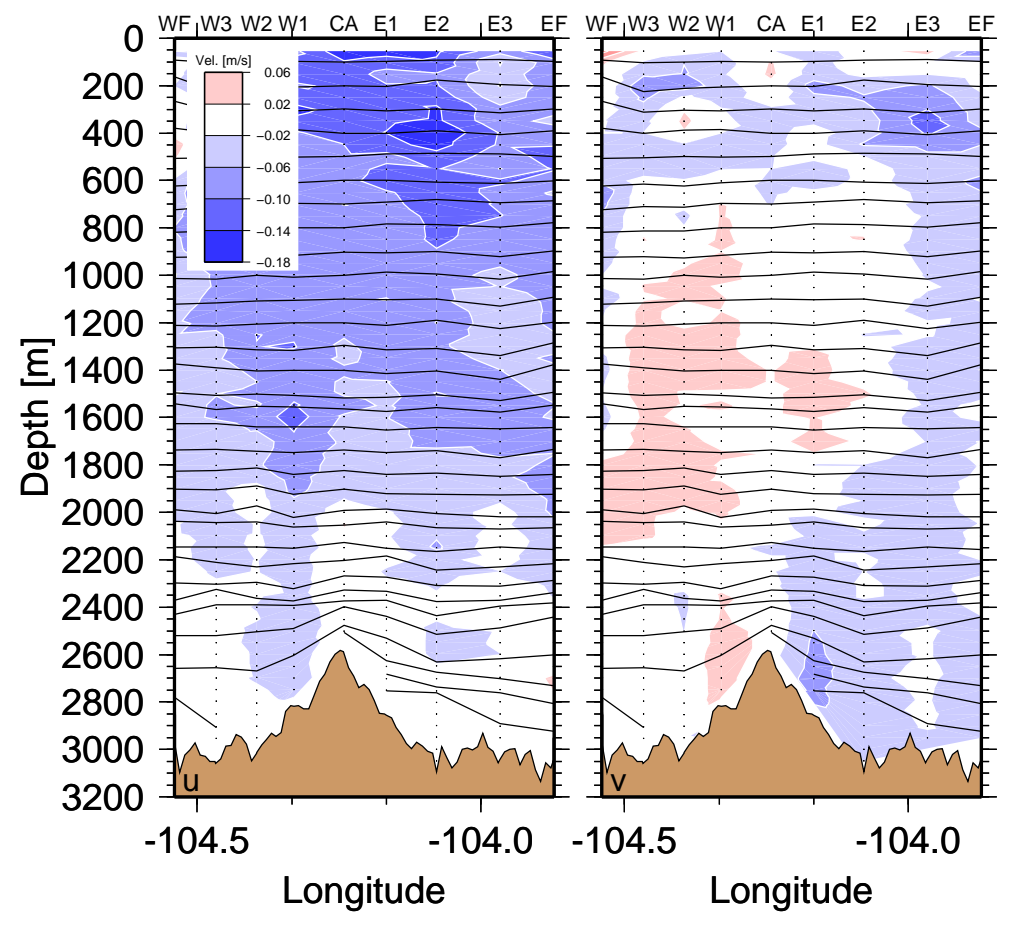

Fig. 6: Temporally averaged LADCP-velocity sections and potential-density contours across the EPR observed during LADDER-1. Each station, labeled above the figure panels, was occupied two or three times at different phases of the semidiurnal tide. The potential density contours are also shown in Fig. 3. Red/blue colors indicate positive/negative velocity components; unshaded regions indicate speeds $<2 \mathrm{~cm} \cdot \mathrm{s}^{-1}$, which is the approximate magnitude of the ensemble-average velocity uncertainties at each station. Left panel: Zonal velocities. Right panel: Meridional velocities.

weeks of consistently southward flow (Fig. 8). During all 7 weeks the northward component of the alongflank flow generally increased with increasing depth between 2400 and $2700 \mathrm{~m}$. In contrast to the alongflank velocities, the weekly averaged cross-flank velocities at W1 during the tracer-release experiment were characterized by comparatively small temporal variability and little vertical structure.

As part of the LADDER project, a high-resolution numerical circulation model was constructed to simulate the regional velocity field during the tracer-release experiment (Lavelle et al., 2010). While the model forcing was derived from velocity measurements at $\mathrm{CA}$ alone, the model has significant skill in simulating the flow in the entire study region, as is apparent from a comparison of our Fig. 8 with Fig. 13 of Lavelle et al. (2010), and by the generally good agreement between the simulated and observed tracer distributions (ibid.). Therefore, the model can be used to put the LADDER measurements into context. For example, the model simulation indicates that the observed differences in vertical structure of the northward along-flank flow at W1 between weeks $1 / 2$ and 3/4 (Fig. 8) primarily reflect a broadening of the along-flank flow during the first half of the tracer experiment (Fig. 12 of Lavelle et al., 2010), rather than a fundamental change in flow structure as suggested by the observations alone.

\subsection{Flow Across the Lamont Seamount Chain}

The topography near the northern end of the EPR segment that constitutes the LADDER study region is dominated by the Lamont Seamount Chain, which rises above the western ridge flank (Fig. 9). With individual peaks reaching depths as shallow as $1650 \mathrm{~m}$ the seamounts extend nearly $1000 \mathrm{~m}$ above the EPR 

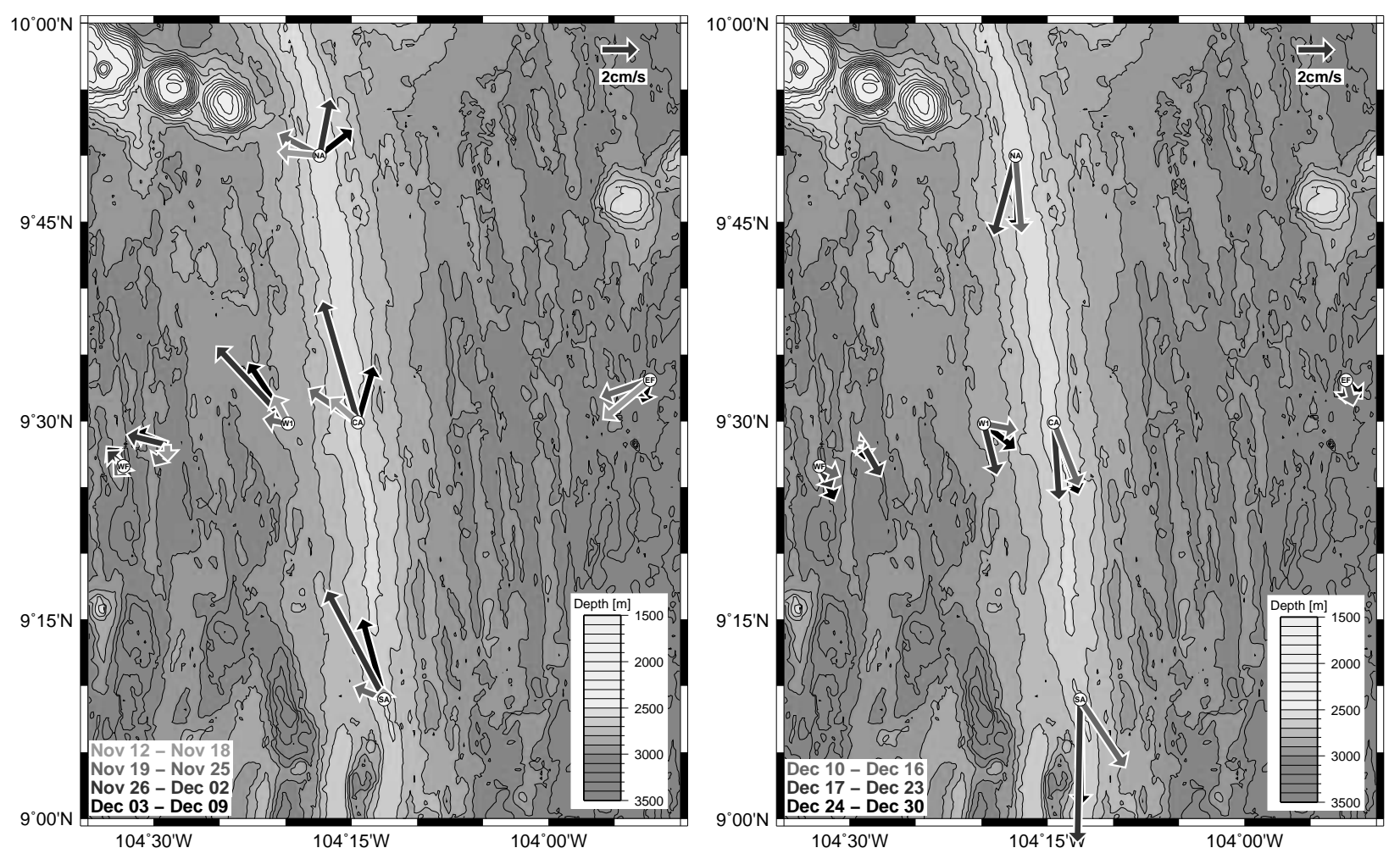

Fig. 7: Weekly averaged velocities at $2450 \mathrm{~m}$ recorded by moored instruments during the tracer-release experiment. Left panel: First four weeks after tracer release, characterized by predominantly north- and westward flow. Right panel: Following three weeks, characterized by predominantly southward flow.

crest. Due to their close spacing the Lamont Seamounts restrict meridional flow near $10^{\circ} \mathrm{N}$ above the western flank of the EPR below $\approx 2000 \mathrm{~m}$ to five narrow $(\approx 2-5 \mathrm{~km})$ passages with sill depths between 2500 and $2800 \mathrm{~m}$ (P1-P5).

The flow across passage P1 between the EPR crest and the easternmost of the Lamont seamounts was sampled with LADCPs during each of the three LADDER cruises (Fig. 10). Below $\approx 2000 \mathrm{~m}$, which coincides with the peak depth of the easternmost seamount, all three velocity profiles obtained during LADDER-1 and -3 are characterized by a 100-200 $\mathrm{m}$ thick layer of southward flow near the seabed underlying a layer of variable but weak flow above. (The arrows in Fig. 9 show the velocities at $2450 \mathrm{~m}$, i.e. above the layer of southward flow.) This contrasts with the situation encountered during the tracer-sampling cruise (LADDER2) when three velocity profiles collected in passage P1 all show consistently southward flow below $2000 \mathrm{~m}$, with the velocities decreasing from a maximum of $\approx 10 \mathrm{~cm} \cdot \mathrm{s}^{-1}$ between 2300 and $2500 \mathrm{~m}$ to zero near the seabed. Results from the regional circulation model indicate weak and variable mean flow below $2000 \mathrm{~m}$ across P1 during LADDER-1 and strong southward flow during LADDER-2 (red curve in Fig. 17B of Lavelle et al., 2010, where "Period 1" corresponds to LADDER-1 and "Period 3" to LADDER-2), further increasing our confidence in the model simulation.

During LADDER-3 the velocities in the remaining deep passages between the seamounts (P2-P5) were also sampled with a LADCP system (Figures 9 and 11). Below $2000 \mathrm{~m}$ the observed flow across the seamount chain was predominantly to the north (northeast across P4) with mean velocities between $0.7 \mathrm{~cm} \cdot \mathrm{s}^{-1}(\mathrm{P} 1)$ and $6.0 \mathrm{~cm} \cdot \mathrm{s}^{-1}(\mathrm{P} 4)$. In the passages $\mathrm{P} 2, \mathrm{P} 3$ and $\mathrm{P} 4$ the north(-east)ward flow across the seamount chain observed during LADDER-3 was bottom intensified and associated with peak speeds between $\approx 10$ and $25 \mathrm{~cm} \cdot \mathrm{s}^{-1}$. The velocity profiles collected in the passages between the seamounts during LADDER-3 are associated with large temporal variability (Figures 10c and 11). Of particular interest are the four velocity profiles from passage 


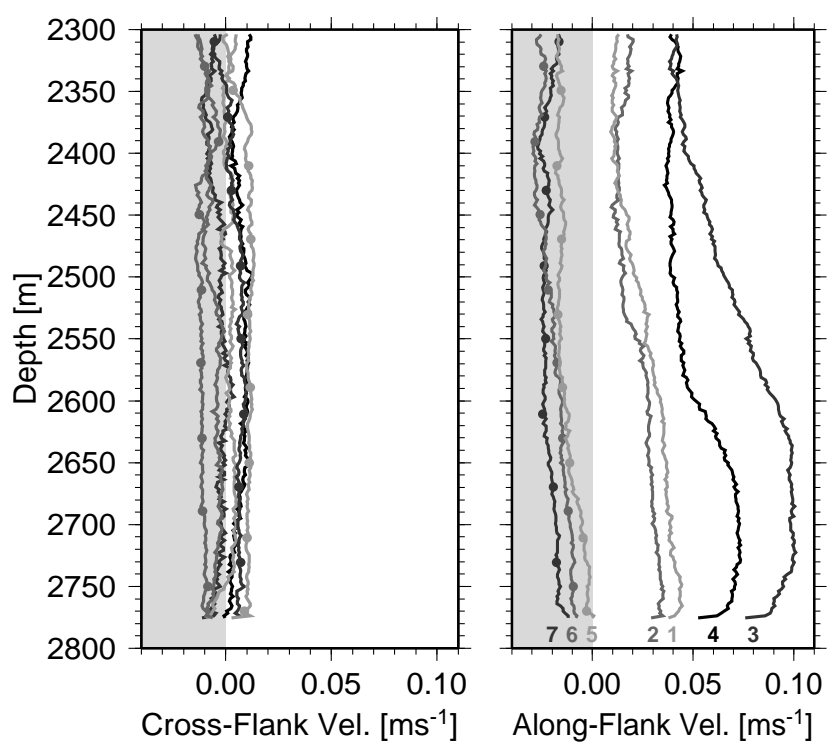

Fig. 8: Weekly averaged velocity profiles recorded by the W1 MMP during the tracer-release experiment. Different shades are used for different weeks, with the week number listed below each profile in the right panel. Left panel: Cross-flank velocities ( $50^{\circ}$ true). Right panel: Along-flank velocities $\left(320^{\circ}\right.$ true).

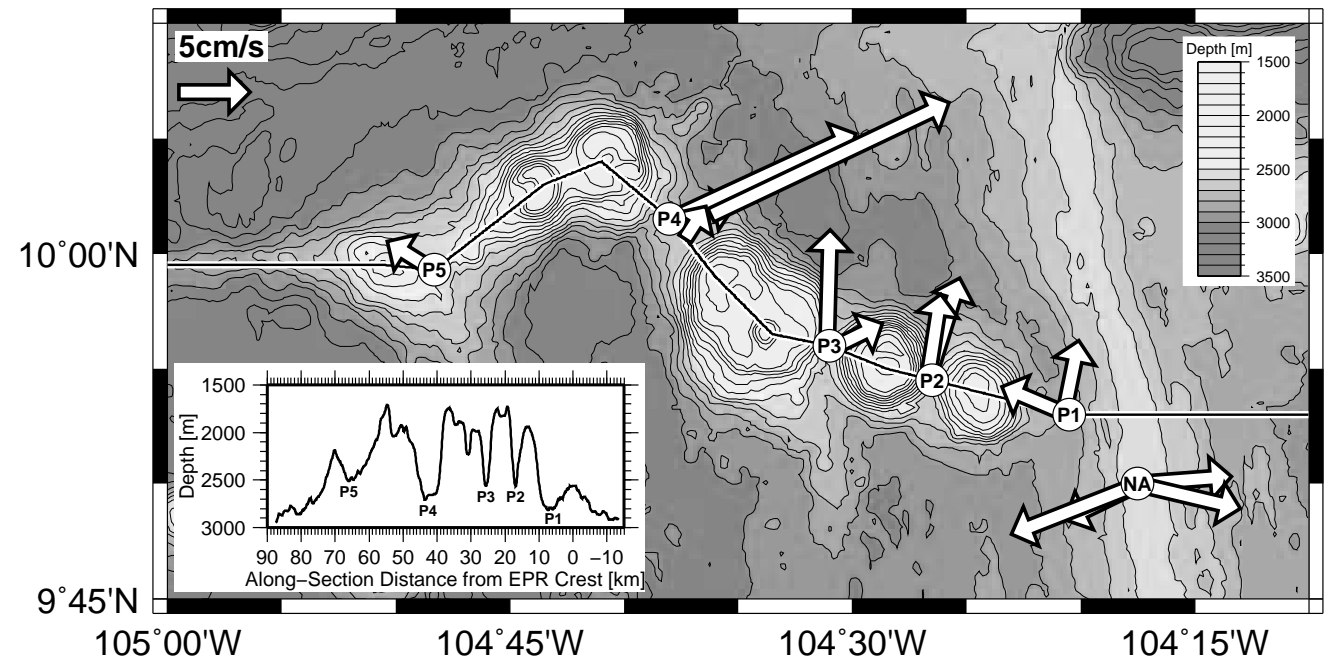

Fig. 9: Lamont Seamount Chain topography and instantaneous LADDER-3 LADCP velocities averaged over $100 \mathrm{~m}$-thick layers centered at $2450 \mathrm{~m}$. The track of the topographic section shown in the inset is marked in the main panel with a thin line. The deep passages with sill depths $>2500 \mathrm{~m}$ between the EPR and the seamounts are labeled P1-P5.

$\mathrm{P} 4$, which are similar above $1500 \mathrm{~m}$ or so but cluster into two groups characterized by velocity differences of $\approx 10 \mathrm{~cm} \cdot \mathrm{s}^{-1}$ below that depth (Fig. 11). The LADDER current-meter data indicate that the temporal variability in the semi-diurnal band accounts for between 55 and $72 \%$ of the variance on time scales shorter than 5 days in this region (not shown). Therefore, it seems reasonable to hypothesize that the temporal variability observed during LADDER-3 in the passages between the seamounts was also dominated by the 


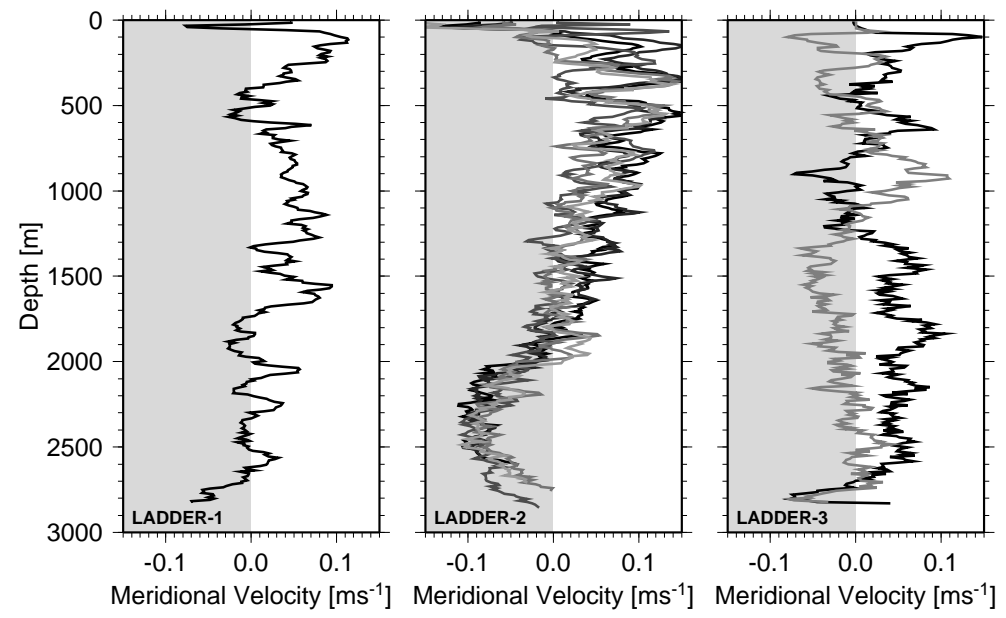

Fig. 10: LADCP-derived instantaneous meridional velocities near the saddle (sill) of passage P1 between the EPR crest and the easternmost peak of the Lamont Seamount Chain observed during the three LADDER cruises (LADDER-1: 1 profile, LADDER-2: 5 profiles collected over 15 days, LADDER-3: 2 profiles collected over 2 days). The darkest and lightest profiles of the LADDER- 2 and -3 data sets are both characterized by relative phase differences of the $\mathrm{M}_{2}$ tide of $155^{\circ}$.

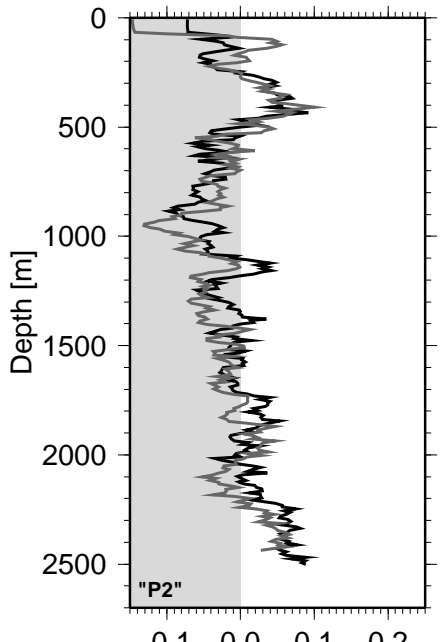

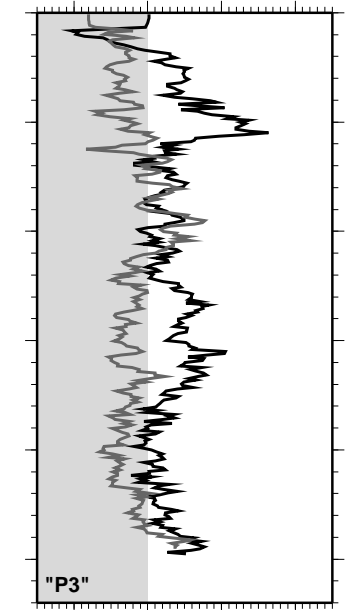

$\begin{array}{llll}-0.1 & 0.0 & 0.1 & 0.2\end{array}$

Meridional Velocity $\left[\mathrm{ms}^{-1}\right]$ Meridional Velocity $\left[\mathrm{ms}^{-1}\right]$

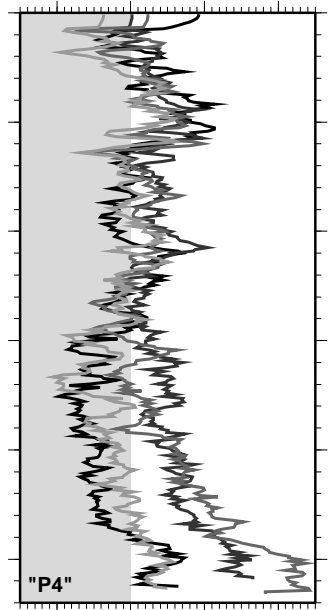

$\begin{array}{llll}-0.1 & 0.0 & 0.1 & 0.2\end{array}$

NE-ward Velocity $\left[\mathrm{ms}^{-1}\right]$

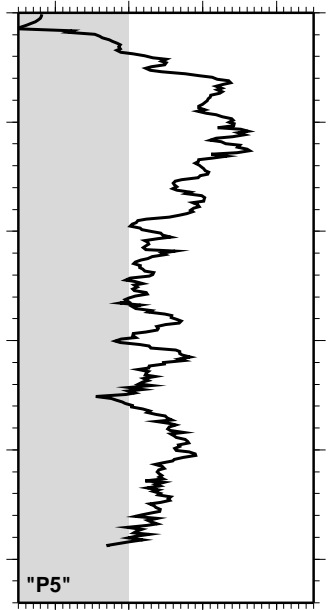

$\begin{array}{llll}-0.1 & 0.0 & 0.1 & 0.2\end{array}$

Fig. 11: Instantaneous LADCP-derived velocity profiles in passages P2-P5 observed during LADDER-3. In each panel, later profiles are shaded lighter than earlier profiles. P2: 2 meridional velocity profiles collected $49 \mathrm{hr}$ apart. P3: 2 meridional velocity profiles collected $71 \mathrm{hr}$ apart. P4: 4 northeastward $\left(45^{\circ}\right.$ true) velocity profiles collected 72, 50 and $3 \mathrm{hr}$ apart. P5: Meridional velocity profile.

$\mathrm{M}_{2}$ tide. This hypothesis is consistent with the timing of the $\mathrm{P} 4$ profiles, as the $\mathrm{M}_{2}$ phase differences between the similar profiles $\left(29 \pm 2^{\circ}\right)$ are considerably smaller than the corresponding phase differences between the dissimilar profiles $\left(81 \pm 29^{\circ}\right)$. Even more striking in this respect are the LADCP data collected in the P1 passage during LADDER-3 (Fig. 10c): While both meridional velocity profiles show the same thin layer of southward flow near the seabed, they resemble mirror images of each other above that layer. As the second 


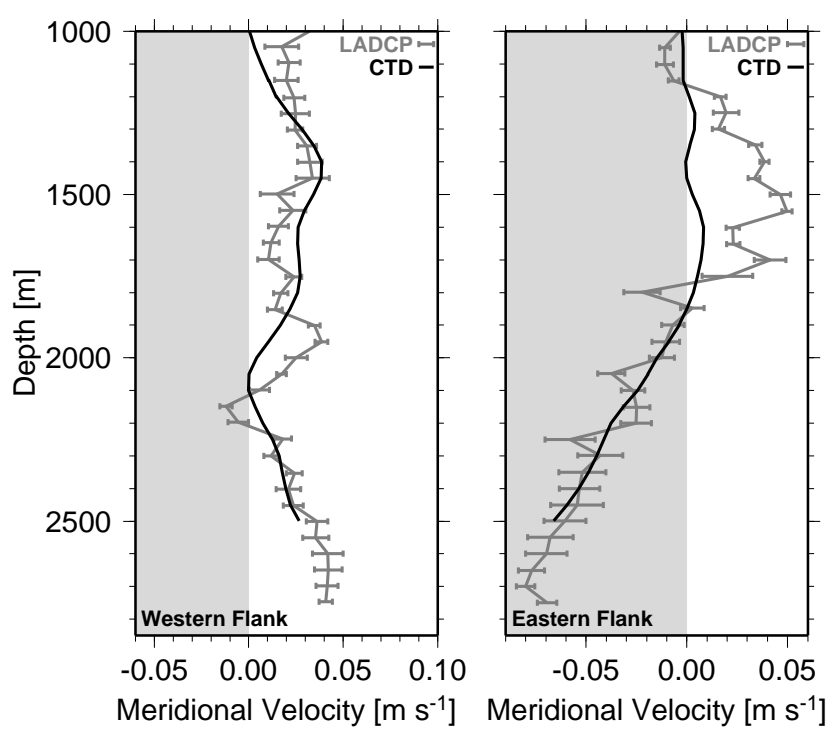

Fig. 12: Temporally averaged meridional velocities in the cores of the ridge-crest boundary currents observed during LADDER-1. Left panel: Velocities at W1. Right panel: Velocities at E1. Error bars of the ensembleaveraged LADCP profiles indicate standard errors, estimated assuming that the individual LADCP profiles are unbiased and independent. The profiles labeled "CTD" are derived from arbitrarily referenced vertically integrated geostrophic shear calculated from the bracketing CTD stations (W2, CA, and E2).

profile was taken 2.4 semi-diurnal tidal periods after the first one $\left(155^{\circ} \mathrm{M}_{2}\right.$ phase difference), the velocity differences are most likely dominated by the local internal $\mathrm{M}_{2}$ tide, which appears similar to a standing wave with an amplitude of $\approx 10 \mathrm{~cm} \cdot \mathrm{s}^{-1}$. Fortuitously, two of the repeat profiles collected in passage P1 during LADDER-2 (Fig. 10b) are also characterized by a $\mathrm{M}_{2}$ phase difference of $155^{\circ}$, but the velocity differences are both qualitatively and quantitatively very different from those observed during LADDER-3. From this we infer that the internal tide in this region is associated with significant temporal variability.

\section{Synthesis of Observations}

The subinertial circulation near the EPR crest between $9^{\circ}$ and $10^{\circ} \mathrm{N}$ observed during LADDER- 1 was characterized by westward flow of several $\mathrm{cm} \cdot \mathrm{s}^{-1}$ across the ridge axis and similarly strong, narrow northward- and southward-flowing "ridge-crest boundary currents" along the western and eastern flanks, respectively. While these along-flank flows extended only a few hundred meters above the crest depth, the westward currents spanned the entire water column. The yearly averaged velocities from the LADDER mooring array show qualitatively similar patterns at and below the depth of the regional hydrothermal plumes (the velocities at higher levels were not sampled by the moored instruments), although the yearly-averaged speeds are significantly smaller than those observed during LADDER-1. Additionally, the LADDER-3 LADCP data are also characterized by mean westward flow between the EPR crest and the sea surface, and by northward flow along the western EPR flank close to the crest (not shown), but sampling on the eastern flank was insufficient to determine the direction and strength of the flow there. The thin, bottom-intensified layer of southward flow observed in the saddle between the EPR crest and the easternmost of the Lamont seamounts both during LADDER-1 \& -3 adds support to the inference that the circulation during those two surveys was similar. In contrast, the regional circulation during LADDER-2 was neither characterized by westward cross-ridge flow, nor by anticyclonically sheared ridge-crest boundary currents but, rather, by mean southward flow across the entire LADDER current-meter array. 
Away from the Lamont Seamount Chain the horizontal density gradients near the EPR crest observed during LADDER were dominated by the cross-ridge component. Centered directly over the crest there was a layer of anomalously high density extending $10-15 \mathrm{~km}$ off axis over both flanks and a few hundred $\mathrm{m}$ above the topography. If a layer-of-no-meridional-motion is assumed farther up in the water column the horizontal density gradients associated with the isopycnal dome over the EPR crest is consistent with anticyclonically sheared meridional flows over the upper ridge flanks. Additionally, the regions of the steepest isopycnal slopes associated with the doming coincide with the cores of the along-flank boundary currents observed during LADDER-1, suggesting that the isopycnal doming is the hydrographic expression of the ridge-crest boundary currents. This inference is consistent with the agreement between the geostrophic vertical shear in the boundary-current cores and the corresponding vertical shear of the mean LADCP-derived along-flank flows observed during LADDER-1 (Fig. 12).

\section{Discussion}

The basin-scale helium distribution in the tropical North Pacific and the float trajectory shown in Fig. 2 indicate that the westward year-long zonal flow recorded by the moored instruments of the LADDER array is part of the large-scale circulation, which is characterized by westward mean flow near $10^{\circ} \mathrm{N}$ extending across most of the tropical North Pacific. Whether the westward cross-ridge velocities observed during the LADDER-1 and -3 surveys are related to that large-scale circulation or whether they reflect mesoscale processes is not clear from our analysis. The cross-ridge asymmetry of the density field below the isopycnal dome observed during LADDER-1 is likely related to the westward subinertial flow across the EPR crest at that time. It is commonly observed in stratified flows that isopycnals shoal upstream of topographic obstacles (e.g. Kinder and Bryden, 1990). Whether a particular isopycnal is lifted sufficiently to clear the obstacle or whether the obstacle blocks flow on that isopycnal depends on whether the approaching flow has sufficient kinetic energy to provide the potential-energy increase required for the uplift. For uniformly stratified, steady, rotating flow across a Gaussian ridge, uplift is possible when $N \Delta h / u \gtrsim 1.5$, where $N$ and $u$ are the upstream buoyancy frequency and velocity, respectively, and $\Delta h$ is the required vertical uplift (Pierrehumbert and Wyman, 1985). Using representative values from LADDER-1 $\left(u \approx 2-3 \mathrm{~cm} \cdot \mathrm{s}^{-1}\right.$, $\left.N \approx 4 \times 10^{-4} \mathrm{~s}^{-1}\right) h \approx 100 \mathrm{~m}$, which is consistent with the isopycnal uplift observed over the eastern EPR flank during LADDER-1 (Figures 3 and 6). Regardless of what causes the isopycnal uplift over the eastern ridge flank, the corresponding cross-flank density gradients are expected to be geostrophically balanced by vertical shear in the along-flank flow, which provides a plausible explanation for the observation that the eastern-flank southward ridge-crest boundary current observed during LADDER-1 was stronger and broader than the corresponding northward flow along the western flank.

While a detailed analysis of the dynamics of the ridge-crest boundary currents, which extend no more than $20 \mathrm{~km}$ off the EPR axis and 100-200 $\mathrm{m}$ above the ridge-crest depth, is beyond the scope of our paper, we note that the inviscid, linear, hydrostatic, 2-layer, Boussinesq model of temporally variable flow across an infinitely long ridge of Allen and Thomson (1993) does not predict any mean crest-parallel currents. On the other hand, ridge-crest boundary currents that are qualitatively and quantitatively very similar to the LADDER observations are reproduced by the 2-D numerical model of McGillicuddy et al. (2010) and by the 3-D model of Lavelle et al. (2010), both of which include friction, mixing and non-linear terms in the equations of motion. Since the low-frequency forcing in the model of McGillicuddy et al. (2010) is nearly zero, we conclude that the ridge-crest boundary currents result from topographic rectification of temporally varying forcing, and that their dynamics depend on friction, mixing and/or advection of momentum.

The LADDER observations and model simulations of anticyclonically sheared along-flank boundary currents near the EPR crest are remarkably similar to observations from the Juan de Fuca Ridge near $45^{\circ} \mathrm{N}$ (Cannon et al., 1991; Cannon and Pashinski, 1997; Helfrich et al., 1998). In that region, too, there are anticyclonically sheared boundary currents associated with mean speeds of several $\mathrm{cm} \cdot \mathrm{s}^{-1}$ a few $\mathrm{km}$ from the ridge crest and limited to off-axial distances of less than $25 \mathrm{~km}$ (Cannon and Pashinski, 1997). While the claim of Helfrich et al. (1998) that the along-ridge flows are strongest at the depth of the regional neutrally buoyant hydrothermal plumes is apparently inconsistent with the LADDER observations and model results 
it is noted that the current meters used by Helfrich et al. (1998) neither sampled the velocities over the ridge flanks below crest level (where the velocities in the boundary currents on the EPR are largest) nor laterally bracketed the velocity maxima on the ridge flanks (their Fig. 2). This implies that the locations of the along-flank velocity maxima are not well constrained by the data of Helfrich et al. (1998).

Near the northern end of the EPR segment studied here the Lamont Seamount Chain topographically constrains the velocity field, in particular the northward boundary current flowing along the western ridge flank. As a result, the largest instantaneous velocities (up to $25 \mathrm{~cm} \cdot \mathrm{s}^{-1}$ ) were observed in the narrow passages between the seamounts. Whereas the LADDER instantaneous velocity measurements everywhere else are dominated by high-frequency (primarily tidal) variability, the data suggest that the direction of flow through the deep passages between the Lamont Seamounts varies on longer time scales and may be related to the regional mesoscale circulation. In addition to large mean velocities and significant vertical shear, the flow in the seamount passages is also characterized by high-vertical-mode internal tides with amplitudes on the order of $10 \mathrm{~cm} \cdot \mathrm{s}^{-1}$. Both these observations suggest that diapycnal mixing in the seamount passages may be elevated.

The weekly averaged current-meter data presented in Section 4.3 indicate a high degree of coherence of the sub-inertial circulation above the EPR during the LADDER tracer-release experiment across most of the study region. Notably, however, the flow recorded only $\approx 35 \mathrm{~km}$ off axis over the eastern ridge flank shows little coherence with the velocities recorded by the remaining instruments. This suggests that the circulation transition between LADDER-1 \& -2 and, hence, the southward flow observed during LADDER-2, is not simply caused by the passage of a mesoscale eddy, as this would be expected to affect all current-meter records. Inspection of all weekly-averaged velocity maps indicates that the sub-inertial circulation is highly variable and, at least some of the time, associated with significant inhomogeneities over small horizontal scales. This implies that dispersal trajectories derived from single-point current-meter records in this region are unlikely to be accurate, as they implicitly assume that the velocity field is horizontally homogeneous over the region of dispersion ( $>150 \mathrm{~km}$ along axis and $>50 \mathrm{~km}$ off axis in case of the calculations of Marsh et al., 2001).

The WOCE P04 hydrographic section occupied in 1989 indicates that, away from the immediate vicinity of the EPR axis, the isopycnals dip downward into the topography over the ridge flanks, which extend more than $2800 \mathrm{~km}$ west and $800 \mathrm{~km}$ east of the ridge crest. Isopycnals and isotherms dipping downward over ridge flanks are commonly observed in hydrographic sections crossing mid-ocean ridges (e.g. Thompson and Johnson, 1996; Thurnherr and Speer, 2003). While it is tempting to ascribe these observations to the effects of bottom-enhanced diapycnal mixing over the ridge flanks, possibly in conjunction with geothermal heating, the vertical scales of the observed layers where the isopycnals dip into the ridge flanks are too large to be consistent with diffusive boundary layers, such as the ones described by Wunsch (1970) and by Phillips (1970), which are associated with vertical scales of no more than a few 10s of m (Thurnherr and Speer, 2003). In order to reproduce the observed vertical scale of the layer of dipping isotherms over the western flank of the EPR with a numerical model, Thompson and Johnson (1996) had to postulate that water parcels remain within the region of enhanced ridge-flank mixing for 30 years, which is clearly inconsistent with the sub-inertial circulation observed during LADDER. The observation that the deep isopycnals during WOCE P04 sloped downward toward the east not just over the western flank of the EPR but also over the relatively flat abyssal plain between $200^{\circ}$ and $230^{\circ} \mathrm{E}$ (Fig. 1) implies that the processes causing the thick layers of dipping isopycnals and isotherms over the flanks of mid-ocean ridges are not yet fully understood.

ACKNOWLEDGMENTS. Co-funding of the LADDER project by the biological and physical oceanography divisions of the National Science Foundation under grants OCE-0425361 and OCE-0424953 is gratefully acknowledged, as is support of J.W. Lavelle by NOAA's Pacific Marine Environmental Laboratory and by the NOAA Vents Program. In addition to the co-authors of this study and the very capable and helpful officers and crew of the R/V Atlantis II, collection and calibration of the LADDER PO data involved several students (A. Guan, F. Terenzi, A. Kohli, X. Liang, J. Stewart), two post-doctoral researchers (A. Ruíz Angulo, R. Jackson), as well as a mooring group from WHOI (S. Worrilow, B. Hogue, P. Fraser). Without the excellent data collected during the WOCE P04 cruise in 1989 it would not have been possible to put the LADDER 
data into a wider context. M. Visbeck donated the neutrally buoyant float deployed on the EPR crest in 2006 .

\section{References}

Allen, S. E. Thomson, R. E., 1993. Bottom-trapped subinertial motions over midocean ridges in a stratified rotating fluid. J. Phys. Oceanogr. 23, 566-581.

Baker, E. T., Chen, Y. J., Morgan, J. P., 1996. The relationship between near-axis hydrothermal cooling and the spreading rate of mid-ocean ridges. Earth Planet. Sci. Lett. 142, 137-145.

Baker, E. T., Feely, R. A., Mottl, M. J., Sansone, F. T., Wheat, C. G., Resing, J. A., 1994. Hydrothermal plumes along the East Pacific Rise, $8^{\circ} 40^{\prime} \mathrm{N}$ to $11^{\circ} 50^{\prime} \mathrm{N}$ : Plume distribution and relationship to the apparent magmatic budget. Earth Planet. Sci. Lett. 128, 1-17.

Cannon, G. A., Pashinski, D. J., Lemon, M. R., 1991. Mid-depth flow near hydrothermal venting sites on the southern Juan de Fuca Ridge. J. Geophys. Res. 96, 12815-12831.

Cannon, G. A. Pashinski, D. J., 1997. Variations in mean currents affecting hydrothermal plumes on the Juan de Fuca Ridge. J. Geophys. Res. 102, 24965-24976.

Clarke, W. B., Beg, M. A., Craig, H., 1969. Excess ${ }^{3}$ he in the sea: evidence for terrestrial primordial helium. Earth Planet. Sci. Lett. 6, 213-220.

Flierl, G. R. McWilliams, J. C., 1978. On the sampling requirements for measuring moments of eddy variability. J. Mar. Res. 35, 797-820.

Fornari, D. J., Haymon, R. M., Perfit, M. R., Gregg, T. K. P., Edwards, M. H., 1998. Axial summit trough of the East Pacific Rise $9^{\circ}-10^{\circ} \mathrm{N}$ : Geological characteristics and evolution of the axial zone on fast spreading mid-ocean ridges. J. Geophys. Res. 103, 9827-9855.

German, C. R., Richards, K. J., Rudnicki, M. D., Lam, M. M., Charlou, J. L., the FLAME Scientific Party, 1998. Topographic control of a dispersing hydrothermal plume. Earth Planet. Sci. Lett. 156, $267-273$.

Helfrich, K. R., Joyce, T. M., Cannon, G. A., Harrington, S. A., Pashinski, D. J., 1998. Mean hydrographic and velocity sections near Pipe Organ vent at Juan de Fuca Ridge. Geophys. Res. Lett. 25, $1737-1740$.

Jackson, P. R., Ledwell, J. R., Thurnherr, A. M., 2010. Dispersion of a tracer on the East Pacific Rise $\left(9^{\circ} \mathrm{N}\right.$ to $\left.10^{\circ} \mathrm{N}\right)$, including the influence of hydrothermal plumes. Deep Sea Res. I 57, 37-52.

Kinder, T. H. Bryden, H. L., 1990. Aspiration of deep waters through straits. In L. J. Pratt (Ed.), The Physical Oceanography of Sea Straits, pp. 295-319. Kluwer Acad., Norwell, Mass.

Kunze, E., Firing, E., Hummon, J. M., Chereskin, T. K., Thurnherr, A. M., 2006. Global abyssal mixing inferred from Lowered ADCP shear and CTD strain profiles. J. Phys. Oceanogr. 36, $1553-1576$.

Lavelle, J. W., Mullineaux, L. S., Thurnherr, A. M., Ledwell, J. R., McGillicuddy, D. J., 2010. Deep ocean circulation and transport where the East Pacific Rise at 9-10 $\mathrm{N}$ meets the Lamont Seamount chain. J. Geophys. Res. Oceans (in press).

Lupton, J., 1998. Hydrothermal helium plumes in the Pacific Ocean. J. Geophys. Res. 103, $15853-15868$.

Macdonald, K. C., Fox, P. J., Miller, S., Carbotte, S., Edwards, M. H., Elsen, M., Fornari, D. J., Perram, L., Pockalny, R., Scheirer, D., Tighe, S., Welland, C., Wilson, D., 1992. The East Pacific Rise and its flanks $8-18^{\circ} \mathrm{N}$ : History of segmemntation, propagation and spreading direcion based on SeaMARC II and Sea Beam studies. Marine Geophysical Researches 14, 299-344.

Marsh, A. G., Mullineaux, L. S., Young, C. M., Manahan, D. T., 2001. Larval dispersal potential of the tubeworkm riftia pachyptila at deep-sea hydrothermal vents. Nature 411, 77-80.

McGillicuddy, D. J., Lavelle, J. W., Thurnherr, A. M., Kosnyrev, V. K., Mullineaux, L. S., 2010. Larval dispersion along an axially symmetric mid-ocean ridge. Deep Sea Res. I, 10.1016/j.dsr.2010.04.003. 
Mullineaux, L. S. et al., in prep. ? Deep Sea Res.

Mullineaux, L. S., Thurnherr, A. M., Ledwell, J. R., McGillicuddy, D. J., Lavelle, J. W., 2008. Larval dispersal on the deep East Pacific Rise. http://www.whoi.edu/projects/LADDER.

Phillips, O. M., 1970. On flows induced by diffusion in a stably stratified fluid. Deep Sea Res. 17, 435-443.

Pierrehumbert, R. T. Wyman, B., 1985. Upstream effects of mesoscale mountains. J. Atmos. Sci. 42, 977-1003.

Polzin, K. L., Toole, J. M., Ledwell, J. R., Schmitt, R. W., 1997. Spatial variability of turbulent mixing in the abyssal ocean. Science 276, 93-96.

Reid, J. L., 1997. On the total geostrophic circulation of the Pacific Ocean: flow patterns, tracers, and transports. Progr. Oceanogr. 39, 263-352.

Speer, K. G., Maltrud, M. E., Thurnherr, A. M., 2003. A global view of dispersion above the mid-ocean ridge. In P. E. Halbach, V. Tunnicliffe, and J. R. Hein (Eds.), Energy and Mass Transfer in Marine Hydrothermal Systems, Number 89 in Dahlem Workshop Report, pp. 287-302. Berlin: Dahlem University Press.

Thompson, L. Johnson, G. C., 1996. Abyssal currents generated by diffusion and geothermal heating over rises. Deep Sea Res. 43, 193-211.

Thomson, R. E., Mihaly, S. F., Rabinovich, A. B., McDuff, R. E., Veirs, S. R., Stahr, F. R., 2003. Constrained circulation at Endeavour ridge facilitates colonization by vent larvae. Nature 424, 545549.

Thurnherr, A. M. Speer, K. G., 2003. Boundary mixing and topographic blocking on the Mid-Atlantic Ridge in the South Atlantic. J. Phys. Oceanogr. 33, 848-862.

Thurnherr, A. M., St. Laurent, L. C., Speer, K. G., Toole, J. M., Ledwell, J. R., 2005. Mixing associated with sills in a canyon on the mid-ocean ridge flank. J. Phys. Oceanogr. 35, 1370-1381.

Thurnherr, A. M., 2010. A practical assessment of uncertainties in full-depth velocity profiles obtained with Teledyne/RDI Workhorse Acoustic Doppler Current Profilers. J. Atm. Oc. Tech. 27, $1215-1227$.

Toole, J., 2001. McLane Moored Profiler data reduction and processing procedures. WHOI Tech. Report (Nov. 2006 version).

Walter, M., Mertens, C., Stöber, U., German, C. R., Yoerger, D., Sültenfuß, J., Rhein, M., Melchert, B., Baker, E. T., 2010. Rapid dispersal of a hydrothermal plume by turbulent mixing. Deep Sea Res. I 57 , 931-945.

Wunsch, C., 1970. On oceanic boundary mixing. Deep Sea Res. 17, 293-301. 